\title{
Ocular Complication in Cardiac Surgery
}

\author{
Leila Alizadeh Ghavidel, ${ }^{1,}{ }^{*}$ Farideh Mosavi, ${ }^{1}$ and Araz Mohammadzadeh ${ }^{2}$ \\ ${ }^{1}$ Assistant Professor of Ophthalmology, Nikookari Department of Ophthalmology, Tabriz University of Medical Sciences, Tabriz, Iran \\ ${ }^{2}$ Retinal Fellowship of Ophthalmology, Nikookari Department of Ophthalmology, Tabriz University of Medical Sciences, Tabriz, Iran \\ "Corresponding author: Leila Alizadeh Ghavidel, Assistant Professor of Ophthalmology, Nikookari Department of Ophthalmology, Tabriz University of Medical Sciences, Tabriz, \\ Iran. E-mail: alizadeh_ghavidell@yahoo.com
}

Received 2016 November 01; Revised 2016 November 19; Accepted 2016 December 17.

\begin{abstract}
Visual loss after nonocular surgery is rare but devastating. Peak rates of perioperative visual loss are with heart and spine surgery. The two possible main causes of visual loss after cardiac surgery are ischemic optic neuropathy and retinal ischemia due to embolism and / or low perfusion secondary to hemodynamic changes through cardiopulmonary bypass within the retinal, optic nerve and choroidal circulation. Stable preservation of some hemodynamic factors during cardiac surgery seems to be the key to stop visual loss. The purpose of this article is to briefly review perioperative visual loss after cardiac surgery.
\end{abstract}

Keywords: Cardiac Surgery, Ischemic Optic Neuropathy, Retinal Vascular Occlusion, Perioperative Complication

\section{Introduction}

Perioperative ocular injuries in non-ocular surgery are rare, but when they do occur, there may be discomfort and sometimes cause visual loss. Reported eye damages include corneal abrasion, conjunctivitis, blurred vision, red eye, chemical damage, lid hematoma, and visual loss. Corneal abrasion is the most common and blindness was the least commonly reported injuries (1-3).

Perioperative visual loss (POVL) a rare, but potentially demoralizing complication can occur due to damage to any portion of the visual pathways, from the corneas to the occipital lobes, but the most common site of injury is the retina or optic nerve. Supposed mechanisms for these injuries include compression, hypotension, hypoxia, intraoperative hemodynamic conciliation and anemia. However, the exact association of these factors with visual loss has not yet been established (2-4).

Unfortunately, the real incidence of POVL is not known and published rates fluctuate significantly. The incidence of POVL after non-ocular surgeries ranges from $0.002 \%-0.0008 \%$ of all surgeries to as high as $0.2 \%$ of cardiac and spine surgeries. But after cardiac surgery; incidence was estimated as high as $0.06 \%$ and $0.113 \%$ in two recent larger studies $(5,6)$.

Studies of 65,000 and 400,000 patients undergoing anesthesia for all types of surgery at two large academic institutions suggested a low prevalence of POVL in operations except cardiac and spinal surgery and uppermost rates of POVL are with cardiac, spine and orthopedic surgeries (2, 4-7).

The main reasons of visual loss after a non-ocular surgery are central or branch retinal vascular occlusion
(CRAO, BRAO) and ischemic optic neuropathy (ION). Other causes of POVL include cortical blindness and pituitary apoplexy $(4,5,7-9)$.

POVL typically occurs immediately after recovery from anesthesia, although it may be delayed by several days. The prognosis for visual improvement is usually poor (5, $6,10,11)$. Numerous available articles in recent years have enhanced the wakefulness of this impending complication between anesthesiologists, surgeons and ophthalmologists $(6,12)$. This review will update the incidence, assumed risk factors, diagnosis, and treatment of POVL due to cardiac surgery.

\section{Blood Flow in Retina and Optic Nerve Head (ONH)}

The blood supply to the majority of the eye is provided by the ophthalmic artery (OA), the initial intracranial division of the internal carotid artery. Branches of the OA particularly the posterior ciliary arteries (PCAs), central retinal artery (CRA) and pial vessel transfer blood to the retina, choroid and intraorbital part of optic nerve (ON). Circulation of the retina by central retinal artery is end arterial system. The $\mathrm{ON}$ are supplied by multiple pial branches and to a lesser extent by segment of central retinal artery which is running within the optic nerve. The $\mathrm{ONH}$ is supplied by short posterior ciliary arteries and recurrent branches of the Zinn-Haller circle which are surrounding the ONH and at the innermost by retinal circulation $(13,14)$.

The ability of the ON vasculature for autoregulation has potentially significant implications in the pathophysiology of ON ischemia $(10,14)$. Halothane and enflurane cause increase in retinal and reduction in choroidal blood flow $(7,10)$. 


\section{Hemodynamic Changes During Cardiac Surgery}

Cardiopulmonary bypass ( $\mathrm{CPB}$ ) is a form of extracorporeal circulation (ECC). CPB is a procedure that temporarily takes over the function of the heart and lungs and maintains the circulation of blood and the oxygen content of the patient's body during variety of cardiac surgeries, such as coronary artery bypass surgery or heart transplantation. Significant variations occur during CPB include change in homoeostasis, systemic vasodilatation, hypothermia, decrease in hemoglobin concentration from hemodilution and changes in metabolic profile. Hematocrit should not be $<25 \%$ during CPB. It is possibly the most favorable to keep hematocrit close to 35\% with enough blood flow, which would eventually be optimizing the delivery of oxygen to the tissues $(10,14)$.

\section{Corneal Abrasion}

Corneal abrasion is probably the most common eye injury during anesthesia, and perhaps one of the most ignored ones too. Corneal abrasion during anesthesia happens due to direct trauma, lateral or prone positioning, diminished tear creation due to GA and head and neck surgeries, and typically present with pain and failure to open the eye, extreme tearing, foreign body sensation, blurred vision and photophobia (2,15-17).

The reported incidence of corneal abrasion varies ranging from $0.17 \%$ - $44 \%$ depending on the methods used to detect it $(2,15)$.

Treatments include lubricating drops, antibiotic eye drops or ointment. Preventative strategy include removal of contact lenses preoperatively, eyes seal and periodic check backs to make sure that eyes stay closed during surgery $(8,15,18)$

\section{Perioperative Visual Loss (POVL)}

Two major causes of POVL are ION and RVO and other minor causes are cortical blindness (CB) and Pituitary apoplexy. The factors of age, gender, and comorbidities suggest that there are specific patient susceptibilities to some types of POVL that are independent of the surgical procedure. Patients aged 50 years and older were more likely to develop ION and retinal artery occlusion than patients in the 18 - 34 years age range in cardiac surgery, possibly because they are more likely to have systemic vascular occlusive disease. However, patients younger than 18 years had the greatest risk of developing POVL, and CB in particular, among all age groups in spine surgery. Men had 1.3 times higher odds ratio of POVL than women, twice the odds ratio of developing ION, and 1.33 times higher odds ratio of developing retinal artery occlusion, in comparison with women $(5,19,20)$

\section{Retinal Ischemia During Cardiac Surgery}

Mechanisms of perioperative retinal ischemia include retinal emboli, increased ocular venous pressure or a reduction in retinal arterial perfusion pressure or high IOP, atheromatous disease in vessels, inflammation (e.g., giant cell arteritis) and vasospasm. Most common risk factors include inappropriate patient positioning or its accidental movement, compression of the eye and hypotension. After open heart surgery, large numbers of micro emboli (platelets, fat, and crystalline material) circulate in the blood stream. Retinal ischemia can result from cardiac surgery due to reduction in blood flow of the retina if emboli lodge in the retinal artery; in fact an incidence of retinal micro-emboli after open heart surgery is up to $100 \%$ (5, 21, 22). External pressure on the eye, such as from an unsuitable headrest or secondary to an anesthetic mask could raise IOP above the SBP leading to retinal ischemia. Periocular trauma was recognized in the greater number (70\%) of cases $(5,14,21)$.

\section{Retinal Artery Occlusion: Branch and Central Reti- nal Artery Occlusion}

In central retinal artery occlusion (CRAO) blood supply to the entire retina decreases but Branch retinal arterial occlusion (BRAO) affects a portion of retina. Central retinal artery occlusion presents with a unilateral sudden vision loss, cherry-red spot on the macula, whitening appearance of the retina, attenuated arterioles, an afferent pupillary defect and macular/retinal edema. In a study of more than 465,000 patients, the overall incidence of postsurgical central retinal artery occlusion was found to be $0.001 \%$ - 0.07/10,000, but higher in patients aged $>65$ years. Men were almost twice as women to build up retinal artery occlusion $(8,23,24)$.

Experiments showed that retinal artery occlusion secondary to external compression and increased IOP may causes a higher level of ischemia and likewise retinal survival is shorter. It was shown that, by rising IOP in rodents and inducing retinal artery obstruction, periods of retinal ischemia as short as 20 min have produced damage $(14,21)$.

Prognosis of central retinal artery occlusion is poor and no successful treatment exists, therefore associated visual loss is usually permanent. There is a number of managements that can be attempted including I.V. acetazolamide and ocular massage to lower IOP to possibly dislodge an emboli; inhalation of $5 \% \mathrm{CO}_{2}$ in oxygen to aug- 
ment dilation and increase of $\mathrm{O}_{2}$ release and localizing hypothermia to the affected eye $(8,25,26)$.

It has been recommended that the use of a foam cushion with orbital holes may prevent postsurgical central retinal artery occlusion and ION development. Make sure that eyes are correctly positioned and checked occasionally $(7,27)$.

Branch retinal artery occlusion is largely secondary to emboli or vasospasm. This condition usually leads to permanent partial visual field loss $(7,28)$.

\section{Ischemic Optic Neuropathy During Cardiac Surgery}

The most common causes of POVL are the two different forms of ION: Anterior ischemic optic neuropathy (AION) and posterior ischemic optic neuropathy (PION). The type of ION varies depending on the type of surgery performed, with AION occurring most often after cardiac surgery and PION occurring most often after spine surgery in prone position or radical neck dissection $(23,29,30)$. AION develops due to a disturbance of oxygen delivery to the $\mathrm{ONH}$ anterior to the lamina cribrosa that might be secondary to a serious reduction in blood supply or oxygen transportation capability. Possible risk factors include systemic disease (smoking, diabetes, arteriosclerosis, hypertension, hypercholesterolemia, and heart disease) and perioperative excessive weight gain and most common etiology of ION are prolonged CPB time, anesthetic duration $\geq 6$ hour, blood loss of 1,000 $\mathrm{ml}$ or greater and hypotension, higher intraocular or orbital venous pressure, hypothermia, autonomic deviation in optic nerve blood supplying, emboli, vasopressor, direct pressure on the globe and Inflammations (complement activation) $(8,14,23,25,26)$. The procedures most commonly associated with perioperative ION are coronary artery bypass grafting (CABG) and back or spinal surgery $(6,19)$. AION classically presents with painless visual loss, afferent pupillary defect or nonreactive pupil, or altitudinal visual field deficit and disturbance of color vision. AION usually presents between the first and third postoperative days, immediately after recovery from anesthesia, although it may be delayed by several days. Examination of the optic disc usually discovers edema of optic disk, occasionally scattered nerve fiber layer hemorrhage and Optic atrophy over subsequent weeks to months. MRI maybe normal or may show nerve swelling or perineural enhancement. Visual loss may be unilateral or bilateral and severe with count fingers vision or worse $(1,7,10,14)$.

The incidence of ION after cardiac surgeries varies significantly but incidence values from large reviews are between 0.028 and $1.3 \%$, and the overall incidence of AION is $0.024 \%$ following cardiac surgery $(26,30)$.
Treatment choices include the use of corticosteroid and optic nerve fenestration; although fenestration procedure is of no benefit. The prognosis for visual recovery is generally poor. Because all methods of treatment have had limited success, efforts to prevent this complication are of paramount importance and include avoidance of perioperative anemia with early transfusion (almost always indicated when the hemoglobin concentration is less than 6 $\mathrm{g} / \mathrm{dL}$ ). Parameters to stop POVL that should be checked during surgery include the ECG, duration of surgery, intraoperative hypotension, pulse rate, blood pressure, central venous pressure, $\mathrm{PCO} 2, \mathrm{PO} 2$, hematocrit, hemoglobin, $\mathrm{Na}, \mathrm{K}$, urine output and temperature of body and blood (within the machine). Correction of any of these underlying factors may be beneficial $(10,26,30,31)$.

\section{Cortical Blindness}

Cortical blindness occurs commonly after cardiac or vascular surgery, and results from damage to the primary visual cortex in parietooccipital lobe. CB may be due to emboli or cerebral low perfusion, and the incidence of $\mathrm{CB}$ is very rare, although the risk appears to be augmented after vascular surgery or CPB. Embolisms in CABG result from handling of the heart and aorta, atrial fibrillation, hypercoagulability or substance from the bypass pump. Risk factors of $\mathrm{CB}$ include: hypertension, diabetes mellitus, renal failure, smoking, COPD and cardiac disease $(5,19,31,32)$.

Complete CB present with bilateral loss of vision, disturbance in the judgment of distance and size, absence of lid reflex response to threat and normal pupillary reflex, eye movements, retina and ON. Total blindness from $\mathrm{CB}$ is rare. Symptoms may be immediate, identified in the first postoperative day, or delayed. The prognosis of postoperative $\mathrm{CB}$ ranges from total permanent visual loss to short episode of visual loss with full recovery $(8,19,21,31,33)$.

\section{Pituitary Apoplexy}

Perioperative pituitary apoplexy is rare and occurs most often after cardiac surgery, particularly coronary artery bypass graft (CABG), mitral valve restore, and aortic valve replacement. Postoperative pituitary apoplexy, caused by infarction or hemorrhage of pituitary gland and present with sudden onset of headache, meningismus, nausea, visual field defects, unilateral or bilateral vision loss and, ophthalmoplegia $(19,34-36)$.

Mechanism of pituitary apoplexy includes reduced tissue oxygenation, embolism and edema. Risk factors of pituitary apoplexy, include major surgery, variation in blood pressure, hypotension, ventilation with positive pressure 
and anticoagulation. Autopsy study of patients who expired within 10 days of CPB establishes that $15 \%$ had evidence of pituitary apoplexy. The suggested treatment for pituitary apoplexy is high dose corticosteroid and urgent decompression surgery $(19,37,38)$.

\section{Conclusions}

Perioperative visual loss in cardiac surgery is a rare, but devastating problem. Possible causes of POVL following cardiac surgery include; anterior ischemic optic neuropathy, retinal artery occlusion, pituitary apoplexy and cortical blindness. The most serious injuries that are most likely to result in blindness are retinal artery occlusion and ION. The exact pathogenesis and risk factors of these complications stay indefinite, therefore surgeon and anesthesiologist should be aware of the possibility of vision loss in the postoperative time. Currently there are no proven treatments available for AION, retinal artery occlusion, or cortical blindness, although correction of any underlying hemodynamic derangement may be beneficial. A complete preoperative evaluation and an intraoperative assessment of underlying factors are imperative in line to control the hemodynamic status of the patient.

Consultation with ophthalmologist is necessary for patients complaining of postoperative visual disturbance. When an ophthalmologist is consulted, the initial assessment includes examination of pupil reactivity, ophthalmoscopy, and assessment of IOP, eye movement, and visual fields and urgent neuroimaging should be obtained to rule out intracranial pathology if a neurological cause for the visual loss is suspected. Since ION often results in severe permanent loss of vision, it's better for patients, especially those with systemic vascular disease, for whom cardiac surgery with CPB is planned, to be made aware of these probable side effects.

\section{References}

1. Dunker S, Hsu HY, Sebag J, Sadun AA. Perioperative risk factors for posterior ischemic optic neuropathy1 1No competing interests declared. J Am Coll Surg. 2002;194(6):705-10. doi: 10.1016/s1072-7515(02)01210-3.

2. Roth S, Thisted RA, Erickson JP, Black S, Schreider BD. Eye injuries after nonocular surgery. A study of 60,965 anesthetics from 1988 to 1992. Anesthesiology. 1996;85(5):1020-7. [PubMed: 8916818].

3. Obray JB, Long TR, Wass CT. A unique case of subconjunctival hemorrhage in a patient undergoing decompressive lumbar laminectomy. Anesthesiol. 2002;96(1):247-8. doi: 10.1097/00000542-20020100000041.

4. Grover V, Jangra K. Perioperative vision loss: A complication to watch out. J Anaesthesiol Clin Pharmacol. 2012;28(1):11-6. doi: 10.4103/09709185.92427. [PubMed: 22345938].

5. Shen Y, Drum M, Roth S. The prevalence of perioperative visual loss in the United States: a 10-year study from 1996 to 2005 of spinal, orthopedic, cardiac, and general surgery. Anesth Analg. 2009;109(5):1534-45. doi: 10.1213/ane.0b013e3181b0500b. [PubMed: 19713263].
6. Warner ME, Warner MA, Garrity JA, MacKenzie RA, Warner DO. The Frequency of Perioperative Vision Loss. Anesth Analg. 2001;93(6):1417-21. doi: 10.1097/00000539-200112000-00013.

7. Roth S. Perioperative visual loss: what do we know, what can we do?.Br J Anaesth. 2009;103 Suppl 1:31-40. doi: 10.1093/bja/aep295. [PubMed: 20007988].

8. Shaw PJ, Bates D, Cartlidge NE, Heaviside D, French JM, Julian DG, et al. Neuro-ophthalmological complications of coronary artery bypass graft surgery. Acta Neurol Scand. 1987;76(1):1-7. [PubMed: 3498286].

9. Shahian DM, PK S. Symptomatic visual deficits after open heart operations. Ann Thorac Surg. 1989;48(2):275-9.

10. Buono LM, Foroozan R. Perioperative posterior ischemic optic neuropathy: review of the literature. Surv Ophthalmol. 2005;50(1):15-26. doi: 10.1016/j.survophthal.2004.10.005. [PubMed: 15621075].

11. Holy SE, Tsai JH, McAllister RK, KH S. Perioperative ischemic optic neuropathya case control analysis of 126,666 surgical procedures at a single institution. J Anesthesiology. 2009;110(2):246-53.

12. KL P. Committee on professional liability forms a new registry to investigate postoperative blindness. ASA Newsl. 1999;63.

13. Francois J, Fryczkowski A. The blood supply of the optic nerve. Adv Ophthalmol. 1978;36:164-73. [PubMed: 665403].

14. Nenekidis I, Pournaras CJ, Tsironi E, Tsilimingas N. Vision impairment during cardiac surgery and extracorporeal circulation: current understanding and the need for further investigation. Acta Ophthalmol. 2012;90(3):168-72. doi: 10.1111/j.1755-3768.2011.02317.x. [PubMed: 22151627].

15. Eye Rounds. . Perioperative corneal abrasions: Systems-based review and analysis 2012. Available from: http://EyeRounds.org/cases/152perioperative-corneal-abrasions.htm.

16. Cucchiara RF, Black S. Corneal abrasion during anesthesia and surgery. Anesthesiol. 1988;69:978-9.

17. Cross DA, Krupin T. Implications of the effects of general anesthesia on basal tear production. Anesth Analg. 1977;56(1):35-7. [PubMed: 556908].

18. Moos DD, Lind DM. Detection and treatment of perioperative corneal abrasions. J Perianesth Nurs. 2006;21(5):332-8. doi 10.1016/j.jopan.2006.08.001. [PubMed: 17027442] quiz 339-41.

19. Berg KT, Harrison AR, Lee MS. Perioperative visual loss in ocular and nonocular surgery. Clin Ophthalmol. 2010;4:531-46. [PubMed: 20596508]

20. Ozcan MS, Praetel C, Bhatti MT, Gravenstein N, Mahla ME, Seubert $\mathrm{CN}$. The effect of body inclination during prone positioning on intraocular pressure in awake volunteers: a comparison of two operating tables. Anesth Analg. 2004;99(4):1152-8. doi: 10.1213/01.ANE.0000130851.37039.50. [PubMed: 15385367] table of contents.

21. Murthy TS, Bhatia P, Prabhakar T, Gogna R. Postoperative visual loss. Anaesthesiol Clin Pharmacol. 2006;22(1):3.

22. Bateman BT, Schumacher HC, Boden-Albala B, Berman MF, Mohr JP, Sacco RL, et al. Factors associated with in-hospital mortality after administration of thrombolysis in acute ischemic stroke patients: an analysis of the nationwide inpatient sample 1999 to 2002. Stroke. 2006;37(2):440-6. doi: 10.1161/01.STR.0000199851.24668.f1. [PubMed 16397164].

23. Alpert JN, Pena Y, Leachman DR. Anterior ischemic optic neuropathy after coronary bypass surgery. Tex Med. 1987;83(8):45-7. [PubMed: 3499000].

24. Pires CS, Remigio MC, Aguiar MI, Tenorio D, Moraes CR, Cavalcanti HD [Ophthalmologic findings in cardiac transplant recipients]. Arq Bras Oftalmol. 2007;70(5):767-70. [PubMed: 18157299].

25. Lee LA, Roth S, Posner KL, Cheney FW, Caplan RA, Newman NJ. The american society of anesthesiologists postoperative visual loss registryanalysis of 93 spine surgery cases with postoperative visual loss. JAmerican Soc Anesthesiol. 2006;105(4):625-9. 
26. Shapira OM, Kimmel WA, Lindsey PS, Shahian DM. Anterior ischemic optic neuropathy after open heart operations. Ann Thorac Surg. 1996;61(2):660-6. doi: 10.1016/0003-4975(95)01108-0. [PubMed: 8572784].

27. Tice DA. Ischemic optic neuropathy and cardiac surgery. Ann Thorac Surg. 1987;44(6):677. [PubMed:3500683].

28. Herren JI, Kunzelman KS, Vocelka C, Cochran RP, Spiess BD. Angiographic and histological evaluation of porcine retinal vascular damage and protection with perfluorocarbons after massive air embolism. Stroke. 1998;29(11):2396-403. [PubMed: 9804654].

29. Blauth CI, Arnold JV, Schulenberg WE, McCartney AC, Taylor KM. Cerebral microembolism during cardiopulmonary bypass. Retinal microvascular studies in vivo with fluorescein angiography. JThorac Cardiovasc Surg. 1988;95(4):668-76. [PubMed: 3352302].

30. Kalyani SD, Miller NR, Dong LM, Baumgartner WA, Alejo DE, Gilbert TB. Incidence of and risk factors for perioperative optic neuropathy after cardiac surgery. Ann Thorac Surg. 2004;78(1):34-7. doi 10.1016/j.athoracsur.2004.02.015. [PubMed: 15223397].

31. Sadda SR, Nee M, Miller NR, Biousse V, Newman NJ, Kouzis A. Clinical spectrum of posterior ischemic optic neuropathy. Am J Ophthalmol. 2001;132(5):743-50. [PubMed: 11704036].
32. Selim M. Perioperative stroke. N Engl J Med. 2007;356(7):706-13. doi: 10.1056/NEJMra062668. [PubMed: 17301301].

33. Taugher PJ. Visual loss after cardiopulmonary bypass. Am J Ophthalmol. 1976;81(3):280-8. [PubMed: 1258951].

34. Sibal L, Ball SG, Connolly V, James RA, Kane P, Kelly WF, et al. Pituitary apoplexy: a review of clinical presentation, management and outcome in 45 cases. Pituitary. 2004;7(3):157-63. doi: 10.1007/s11102-0051050-3. [PubMed: 16010459].

35. Fyrmpas G, Constantinidis J, Foroglou N, Selviaridis P. Pituitary apoplexy following endoscopic sinus surgery. J Laryngol Otol. 2009;25:1-3.

36. Shapiro LM. Pituitary apoplexy following coronary artery bypass surgery.J Surg Oncol. 1990;44(1):66-8. [PubMed: 2342378].

37. Ayuk J, McGregor EJ, Mitchell RD, Gittoes NJ. Acute management of pituitary apoplexy-surgery or conservative management?. Clin Endocrinol (Oxf). 2004;61(6):747-52. doi:10.1111/j.1365-2265.2004.02162.x. [PubMed: 15579190].

38. Absalom M, Rogers KH, Moulton RJ, Mazer CD. Pituitary apoplexy after coronary artery surgery. Anesth Analg. 1993;76(3):648-9. [PubMed: 8452282]. 